\title{
Effect of Solvent on Catalysis of Protease Adsorbed on Biochar in Organic Media
}

\author{
Hidetaka Noritomi ${ }^{1}$, Jumpei Nishigami ${ }^{1}$, Nobuyuki Endo ${ }^{2}$, Satoru Kato ${ }^{1} \&$ Shinsuke Takagi ${ }^{1}$ \\ ${ }^{1}$ Department of Applied Chemistry for Environment, Tokyo Metropolitan University, Japan \\ ${ }^{2}$ EEN Co., Ltd., Tokyo, Japan \\ Correspondence: Hidetaka Noritomi, Department of Applied Chemistry for Environment, Tokyo Metropolitan \\ University, Japan. E-mail: noritomi@tmu.ac.jp
}

Received: July 12, 2018

Accepted: August 11, 2018

Online Published: September 28, 2018

doi: $10.5539 /$ jmsr.v7n4p46

URL: https://doi.org/10.5539/jmsr.v7n4p46

\begin{abstract}
We have found that the adsorption immobilization of the serine protease $\alpha$-chymotrypsin $(\alpha-\mathrm{CT})$ onto bamboo charcoal powder (BCP), which is a kind of biochar, improves the transesterification rate of $N$-acetyl-L-tyrosine ethyl ester $(N$-Ac-Tyr-OEt) with $n$-butanol $(\mathrm{BuOH})$ in 9 organic solvents. Organic solvents strongly affected the catalysis of BCP-adsorbed $\alpha$-CT. The transesterification rate of BCP-adsorbed $\alpha$-CT was much superior to that of free $\alpha-\mathrm{CT}$ in every organic solvent. Especially, the transesterification rate of BCP-adsorbed $\alpha$-CT was about 760 times higher than that of free $\alpha$-CT in $n$-butyl acetate.
\end{abstract}

Keywords: Adsorption, Biochar, $\alpha$-Chymotrypsin, Catalysis, Solvent effect

\section{Introduction}

An enormous amount of greenhouse gas such as $\mathrm{CO}_{2}$ has recently been emitted from industries, and thereby has caused serious global warming problems (IPCC, 2014; Olivier et al., 2017). Accordingly, the application of biomass materials, which are carbon neutral, to energies and functional materials is crucial to reduce greenhouse gas emissions (Ho \& Show, 2015; Straathof, 2014). However, most of biomass materials such as forestry residues have hardly been utilized in the field of functional materials. Accordingly, the development in the high value-added application of biomass materials has been desired to provide the multiple effective utilization system of biomass materials.

Enzymes are biocatalysts, which exhibit their outstanding biological activity under mild conditions, and have widely been used in pharmacy, biotechnology, and chemical industry (Buchholz et al., 2012; Leech et al., 2012; Silwana et al. 2014). Typical applications of enzymes are biotransformation, biosensor, biofuel cell, and so on. Enzymes are generally stable in a cell. However, they are gradually denatured and inactivated under various physical and chemical stresses such as heat, organic solvents, and so on (Bailey \& Ollis, 1986). In order to enhance the stability of enzymes used in vitro, enzyme immobilization, where enzyme molecules are attached to solid carriers, has widely been used (Elnashar, 2010; Mateo et al., 2007; Zdata et al, 2018). The main required features of enzyme carriers are chemical stability, thermal stability, insolubility under reaction conditions, high affinity to enzymes, biocompatibility, presence of reactive functional groups, availability, price, regeneration, reusability, and so on. When enzymes are immobilized onto carriers through adsorption, the catalytic activity, specificity, and stability of enzymes are influenced by the nature of carriers. Accordingly, the performance of enzymes can be enhanced by selecting an appropriate carrier.

In order to apply biomass materials to enzyme carriers, we have so far examined the adsorption of enzymes onto biochar, which is derived from biomass materials such as forestry residues. We have found that enzymes are effectively adsorbed onto biochar (Noritomi et al., 2013a; Noritomi et al., 2013b), and biochar-adsorbed enzymes exhibit the high thermal stability in water (Noritomi et al., 2011; Noritomi et al., 2012; Noritomi et al., 2014; Noritomi et al., 2016). Moreover, we have reported that the adsorption of enzymes onto biochar sufficiently improve the enzyme activity in acetonitrile (Noritomi et al., 2017a; Noritomi et al., 2017b).

In our present work, we have assessed how the nature of organic solvents affects the catalysis of enzymes adsorbed onto biochar in organic solvents. We have used bovine pancreas $\alpha$-chymotrypsin $(\alpha-C T)$ as a model protein since it is well investigated regarding its structure, functions, and properties (Kumar \& Venkatesu, 2012). 


\section{Method}

\subsection{Materials}

$\alpha$-Chymotrypsin (EC 3.4.21.1 from bovine pancreas) (type II, 52 units/mg solid) ( $\alpha$-CT) was purchased from Sigma-Aldrich Co. (St. Louis, USA). $N$-Acetyl-L-tyrosine ethyl ester ( $N$-Ac-Tyr-OEt) and $N$-acetyl-L-tyrosine $(\mathrm{N}$-Ac-Tyr-OH) were also from Sigma-Aldrich Co. (St. Louis, USA). Organic solvents used in the present work were of guaranteed grade, and were obtained from Kanto Chemical Co. (Tokyo, Japan). All organic solvents were dried by storing them over dry $0.3 \mathrm{~nm}$ molecular sieves (Wako Chemical Co.) for at least $24 \mathrm{~h}$ prior to use.

\subsection{Preparation of Bamboo Charcoal Powder}

To prepare bamboo charcoal as a biochar, under nitrogen atmosphere, bamboo waste was dried at $180^{\circ} \mathrm{C}$ for $2 \mathrm{~h}$, was pyrolyzed at $450{ }^{\circ} \mathrm{C}$ for $2 \mathrm{~h}$, was carbonized at $350{ }^{\circ} \mathrm{C}$ for $3 \mathrm{~h}$, and then was cooled at $100{ }^{\circ} \mathrm{C}$ for $1 \mathrm{~h}$ by pyrolyzer (EE21 Pyrolyzer, EEN Co. Ltd., Japan) (Noritomi et al., 2017b). Bamboo charcoal powder (BCP) was obtained by grinding the resultant bamboo charcoal with jet mill (100AS, Fuji Sangyo Co. Ltd., Japan).

\subsection{Characterization of Bamboo Charcoal Powder}

The SEM micrograph was obtained using a scanning electron microscope (JSM-7500FA, JEOL, Japan) operating at $15 \mathrm{kV}$. The sample for SEM was prepared on a carbon tape without vapor deposition.

All samples were outgassed at $300^{\circ} \mathrm{C}$ for $8 \mathrm{~h}$ prior to the nitrogen adsorption measurements. The specific surface area of BCP was obtained using a micropore system (BELSORP-mini II, BEL JAPAN, INC.), and the pore size distribution was calculated with the use of the micropore analysis method (MP method).

The surface of BCP was analyzed by X-ray photoelectron spectroscopy (XPS) (Quantum-2000, ULVAC-PHI Co. Ltd.) operating at an $\mathrm{x}$-ray beam size of $100 \mu \mathrm{m}$.

\subsection{Adsorption of $\alpha$-Chymotrypsin onto Bamboo Charcoal Powder}

As a typical procedure, $5 \mathrm{~mL}$ of $0.01 \mathrm{M}$ phosphate buffer solution at $\mathrm{pH} 7$ containing $300 \mu \mathrm{M} \alpha-\mathrm{CT}$ and $3 \mathrm{~g} / \mathrm{L}$ BCP was placed in a $10-\mathrm{mL}$ test tube with a screw cup, and was incubated at $25^{\circ} \mathrm{C}$ and $120 \mathrm{rpm}$ for $24 \mathrm{~h}$. After adsorption, the mixture was filtrated with a membrane filter (pore size: $0.1 \mu \mathrm{m}$, Millipore Co. Ltd.). The amount of $\alpha-\mathrm{CT}$ adsorbed onto BCP was calculated by subtracting the amount of $\alpha$-CT included in the supernatant liquid after adsorption from the amount of $\alpha$-CT in the aqueous solution before adsorption. The amount of $\alpha$-CT was measured at $280 \mathrm{~nm}$ by UV/vis spectrophotometer (UV-1800, Shimadzu Co. Ltd.).

\subsection{Measurement of Catalytic Activity of $\alpha$-Chymotrypsin}

The standard reaction for transesterification was carried out as follows: Three milliliter of an organic solvent containing $0.2 \%(\mathrm{v} / \mathrm{v})$ water, $10 \mathrm{mM} \mathrm{N}$-Ac-Tyr-OEt, $1000 \mathrm{mM} n$-butanol, $1 \mathrm{mM}$ acetanilide, and free $\alpha$-CT or BCP-adsorbed $\alpha$-CT $(30 \mu \mathrm{M})$ was placed in a $4 \mathrm{~mL}$ screw-cap vial, and was incubated at $120 \mathrm{rpm}$ and $25^{\circ} \mathrm{C}$. The amounts of the reaction components were periodically determined with HPLC (Shimadzu LC-10A) (Shimadzu Co., Kyoto, Japan) using a TSK-GEL ODS-80TM column (Tosoh Co., Tokyo, Japan) eluted with water-acetonitrile (6:4 by volume) at $0.5 \mathrm{~mL} / \mathrm{min}$ with detection at $270 \mathrm{~nm}$. Acetanilide was used as an internal standard.

\subsection{Measurement of Fourier Transform Infrared (FTIR) Spectroscopy}

FTIR measurements of free $\alpha$-CT and BCP-adsorbed $\alpha$-CT were carried out using a Jasco FT/IR spectrometer model FT/IR-4100. A KBr pellet containing $0.5 \mathrm{mg}$ of free $\alpha$-CT or BCP-adsorbed $\alpha$-CT powder per $100 \mathrm{mg}$ of $\mathrm{KBr}$ was prepared, and the measurements were performed using 512 scans under $4.0 \mathrm{~cm}^{-1}$ resolution.

\section{Results and Discussion}

\subsection{Characterization of Bamboo Charcoal Powder}

Bamboo charcoal has been prepared by pyrolyzing bamboo waste at low temperatures under nitrogen atmosphere to produce functional groups, which were used as a binding site for the adsorption of enzymes. The resultant bamboo charcoal was grinded by jet mill to obtain the fine bamboo charcoal powder (BCP), whose diameter was about $7 \mu \mathrm{m}$.

The surface area of BCP was $294 \mathrm{~m}^{2} / \mathrm{g}$, and was similar to that of a conventional wood charcoal. Figure 1 shows the pore size distribution of BCP. The range of pore diameter was mainly from $0.6 \mathrm{~nm}$ to $1.2 \mathrm{~nm}$, and was much smaller than the size of $\alpha$-CT since the size of $\alpha$-CT is $5.1 \times 4.0$ × $4.0 \mathrm{~nm}$ (Kumar \& Venkatesu, 2012). This result indicates that most of enzymes is adsorbed onto the surface of BCP in direct contact with bulk organic solvents during the enzymatic reaction in organic solvents. 


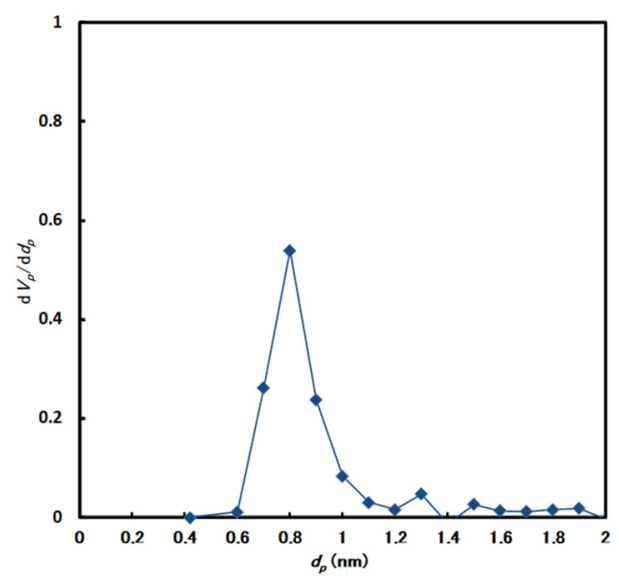

Figure 1. Pore size distribution of bamboo charcoal powder (BCP)

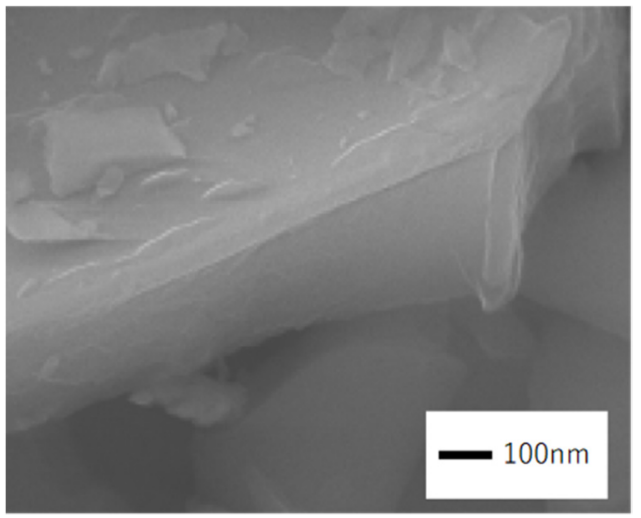

Figure 2. SEM image of bamboo charcoal powder (BCP)

Figure 2 shows the scanning electron micrograph of BCP. The surface of BCP looked like smooth. As mentioned above, since the pore size of BCP was the order of micropores, the pores on the surface of BCP might not be observed under the magnification measured in the present work.

The chemical property of the surface of BCP has been measured by X-ray photoelectron spectroscopy (XPS). The elemental composition and binding state from the surface to $3 \sim 5 \mathrm{~nm}$ depth can be detected by XPS. As shown in Table 1, aromatics, aliphatics, single C-O bond (alcohol, ether, phenol, C-OH of an enol-keto group), double bonded carbon oxygen groups, carbonyl, quinone, and carboxyl groups were mainly detected by waveform separation of $\mathrm{C}_{1}$ peaks of narrow scan spectrum.

The amount of $\alpha$-CT adsorbed onto BCP was $9.8 \mu \mathrm{mol} / \mathrm{g}$. The charge of $\alpha$-CT was positive in the buffer solution at $\mathrm{pH} 7$ since the isoelectric point of $\alpha-\mathrm{CT}$ is 9.1 (Kumar \& Venkatesu, 2012). On the other hand, the $\zeta$-potential of BCP was negative at $\mathrm{pH} 7$ in the buffer solution at pH 7 (Noritomi et al., 2013a). These indicate that the electrostatic force between the positively-charged $\alpha$-CT molecules and the negatively-charged surface of $\mathrm{BCP}$ mainly contributes to the adsorption of $\alpha-\mathrm{CT}$ onto BCP.

Table 1. Waveform separation of $\mathrm{C}_{1 \mathrm{~s}}$ peaks.

\begin{tabular}{llll}
\hline Peak number & Band & Binding energy $(\mathrm{eV})$ & Atomic percentage (\%) \\
\hline 1 & $\mathrm{C}-\mathrm{C}, \mathrm{C}-\mathrm{H}$ & 284.78 & 63.87 \\
2 & $\mathrm{C}-\mathrm{O}$ & 286.12 & 10.93 \\
3 & $\mathrm{O}-\mathrm{C}-\mathrm{O}$ & 287.1 & 3.29 \\
4 & $\mathrm{C}=\mathrm{O}$ & 288.48 & 2.57 \\
5 & $\mathrm{COOH}$ & 289.48 & 0.03 \\
\hline
\end{tabular}




\subsection{Solvent Dependence of Conformation of BCP-Adsorbed $\alpha$-CT}

There have been some reports that the native conformation of enzymes may be altered when enzymes are immersed in organic solvents (Mozhaev et al., 1989; Ryu \& Dordick, 1992). Table 2 shows the ratio of the absorbance at $1650 \mathrm{~cm}^{-1}$ to the absorbance at $1630 \mathrm{~cm}^{-1}\left(\mathrm{ABS}_{1650} / \mathrm{ABS}_{1630}\right)$ of free $\alpha$-CT and BCP-adsorbed $\alpha$-CT after they were immersed in organic solvents for $24 \mathrm{~h}$. The bands at ca. 1650 and $1630 \mathrm{~cm}^{-1}$ are respectively assignable to $\alpha$-helix and intramolecular $\beta$-sheet, which are secondary structures of enzymes (Surewicz \& Mantsch, $1988)$. Before the solvent immersion, the absorbance ratio $\left(\mathrm{ABS}_{1650} / \mathrm{ABS}_{1630}\right)$ of $\mathrm{BCP}$-adsorbed $\alpha$-CT was greater than that of free $\alpha$-CT. The absorbance ratio $\left(\mathrm{ABS}_{1650} / \mathrm{ABS}_{1630}\right)$ of $\mathrm{BCP}$-adsorbed $\alpha$-CT after the solvent immersion was different from that before the solvent immersion. Likewise, the absorbance ratio $\left(\mathrm{ABS}_{1650} / \mathrm{ABS}_{1630}\right)$ of free $\alpha$-CT was altered by the solvent immersion. Moreover, the absorbance ratio $\left(\mathrm{ABS}_{1650} / \mathrm{ABS}_{1630}\right)$ of $\mathrm{BCP}$-adsorbed $\alpha$-CT after acetonitrile immersion was almost similar to that after $n$-octane immersion, while the absorbance ratio $\left(\mathrm{ABS}_{1650} / \mathrm{ABS}_{1630}\right)$ of free $\alpha$-CT after acetonitrile immersion was smaller than that after $n$-octane immersion. The $\alpha$-helical structure of $\alpha$-CT molecule is more changeable than $\beta$-sheet, since the $\beta$-sheet structure is the main backbone of $\alpha$-CT molecule (Kumar \& Venkatesu, 2012). Consequently, the higher absorbance ratio corresponds to the higher secondary structure. Those results indicate that the conformation of BCP-adsorbed $\alpha$-CT is hardly influenced by the nature of solvents, compared to the case of free $\alpha$-CT.

Table 2 Ratio of the absorbance at $1650 \mathrm{~cm}^{-1}$ to the absorbance at $1630 \mathrm{~cm}^{-1}\left(\mathrm{ABS}_{1650} / \mathrm{ABS}_{1630}\right)$ of free $\alpha-\mathrm{CT}$ and $\mathrm{BCP}$-adsorbed $\alpha$-CT provided by the FTIR measurement after the solvent immersion.

\begin{tabular}{llc}
\hline Solvent & \multicolumn{2}{c}{$\mathrm{ABS}_{1650} / \mathrm{ABS}_{1630}(-)$} \\
& Free $\mathrm{a}-\mathrm{CT}$ & $\mathrm{BCP}$-adsorbed $\mathrm{a}-\mathrm{CT}$ \\
\hline None & 1.14 & 1.47 \\
Acetonitrile & 1.15 & 1.51 \\
$n$-Octane & 1.20 & 1.53 \\
\hline
\end{tabular}

\subsection{Solvent Dependence of Catalysis of BCP-Adsorbed $\alpha-C T$}

Figure 3 shows the $\alpha$-CT-catalyzed reaction scheme (Leninger et al., 1993; Wescott et al., 1996). When $\mathrm{N}$-acetyl-L-tyrosine ethyl ester $(\mathrm{N}$-Ac-Tyr-OEt) is used as a substrate, the enzymatic reaction proceeds by the formation of enzyme intermediates between the active site of enzymes and the substrate. In water $\alpha$-CT catalyzes the hydrolysis reaction of $N$-acetyl-L-tyrosine ethyl ester $(N$-Ac-Tyr-OEt) with water to give $N$-acetyl-L-tyrosine $(N-\mathrm{Ac}-\mathrm{Tyr}-\mathrm{OH}) . \mathrm{On}$ the other hand, in organic solvents $\alpha$-CT mainly catalyzes the transesterification reaction of $N$-acetyl-L-tyrosine ethyl ester ( $N$-Ac-Tyr-OEt) with another substrate, $n$-butanol $(\mathrm{BuOH})$ to produce $N$-acetyl-L-tyrosine butyl ester ( $N$-Ac-Tyr-OBu). Thus $\alpha$-CT, which is hydrolase, can beneficially catalyze the synthetic reaction in organic solvents, although expensive energy substances such as adenosine triphosphate (ATP) are needed to take place conventional synthetic reactions by enzymes in water (Leninger et al., 1993).

The catalysis of free $\alpha$-CT and BCP-adsorbed $\alpha$-CT was markedly dependent upon the nature of organic solvents as shown in Fig. 4. The catalytic activity of BCP-adsorbed $\alpha-\mathrm{CT}$ was much superior to that of free $\alpha-\mathrm{CT}$ in organic solvents. The transesterification rate of free $\alpha$-CT in $n$-octane exhibited 813 -fold, compared to that in $n$-butyl acetate, while the transesterification rate of BCP-adsorbed $\alpha$-CT in $n$-octane was 1.3 times greater than that in $n$-butyl acetate.

Figure 5 shows the relation between the catalytic activity and the hydrophobicity defined as $\log \mathrm{P}$ where $\mathrm{P}$ is a partition coefficient for a given solvent between $n$-octanol and water (Laane et al. 1987). The transesterification rate of free $\alpha$-CT and BCP-adsorbed $\alpha$-CT increased with an increase in the hydrophobicity of organic solvents. Likewise, the hydrolysis rate of free $\alpha-\mathrm{CT}$ and BCP-adsorbed $\alpha$-CT tended to increase with increasing the hydrophobicity of organic solvents. The hydrophobicity contributes to the partition of water between enzyme molecules and the bulk organic phase in reaction systems (Klibanov, 2001; Zaks \& Klibanov, 1988). When a certain amount of water is added into organic solvents, the amount of water associated with enzyme molecules increases in an increase in the hydrophobicity of organic solvents. Thereby, the flexibility of enzyme molecules, which is essential for catalytic activity, is enhanced by the hydration of enzyme molecules, and then the catalytic activity increases. On the other hand, hydrolysis reaction is promoted by water molecules around enzymes. As shown in Fig.5, the transesterification rate of BCP-adsorbed $\alpha$-CT was much superior to that of free $\alpha$-CT at the low hydrophobicity. For instance, the transesterification rate of BCP-adsorbed $\alpha$-CT was about 760 times higher than that of free $\alpha$-CT in $n$-butyl acetate $(\log \mathrm{P}=1.7)$. Moreover, BCP-adsorbed $\alpha$-CT depicted the high transesterification rate in acetone and acetonitrile, compared to the case of free $\alpha-\mathrm{CT}$. An enzymatic reaction in hydrophilic solvents has the advantage of the solubility of a variety of substrates including drug derivatives, which 
are poorly soluble in hydrophobic solvents (Kise et al, 1990). As discussed above, since the native conformation of BCP-adsorbed $\alpha$-CT was maintained in hydrophilic organic solvents, BCP-adsorbed $\alpha$-CT could exhibit the high catalytic activity, compared to the case of free $\alpha-C T$. On the other hand, no correlation between the catalytic activity and the other parameter (e.g. dielectric constant, hydrogen bonding parameter, solubility parameter, and viscosity) was shown.
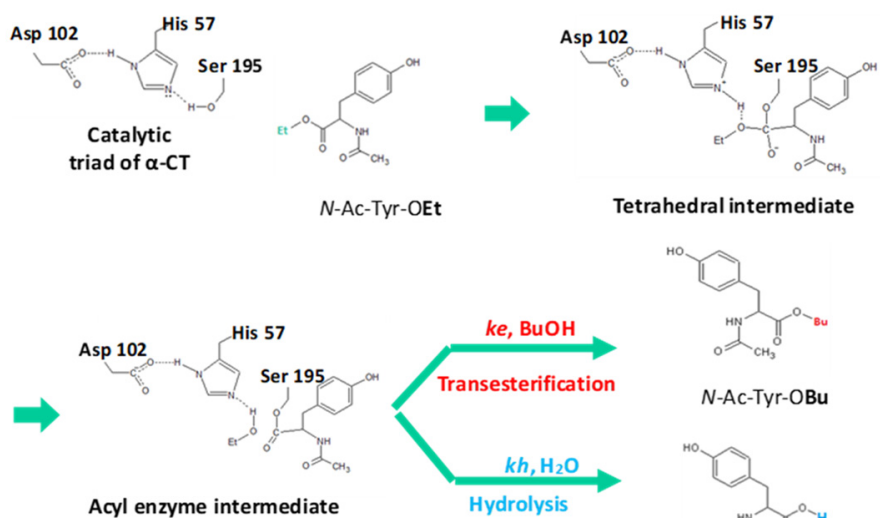

Tetrahedral intermediate

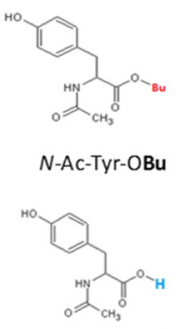

N-AC-Tyr-OH

Figure 3. Reaction scheme of $\alpha$-CT-catalyzed transesterification of $N$-acetyl-L-tyrosine ethyl ester $(N$-Ac-Tyr-OEt) with $n$-butanol $(\mathrm{BuOH})$ to $N$-acetyl-L-tyrosine butyl ester $(N$-Ac-Tyr-OBu) and competing hydrolysis

$(N-$ Ac-Tyr-OH)
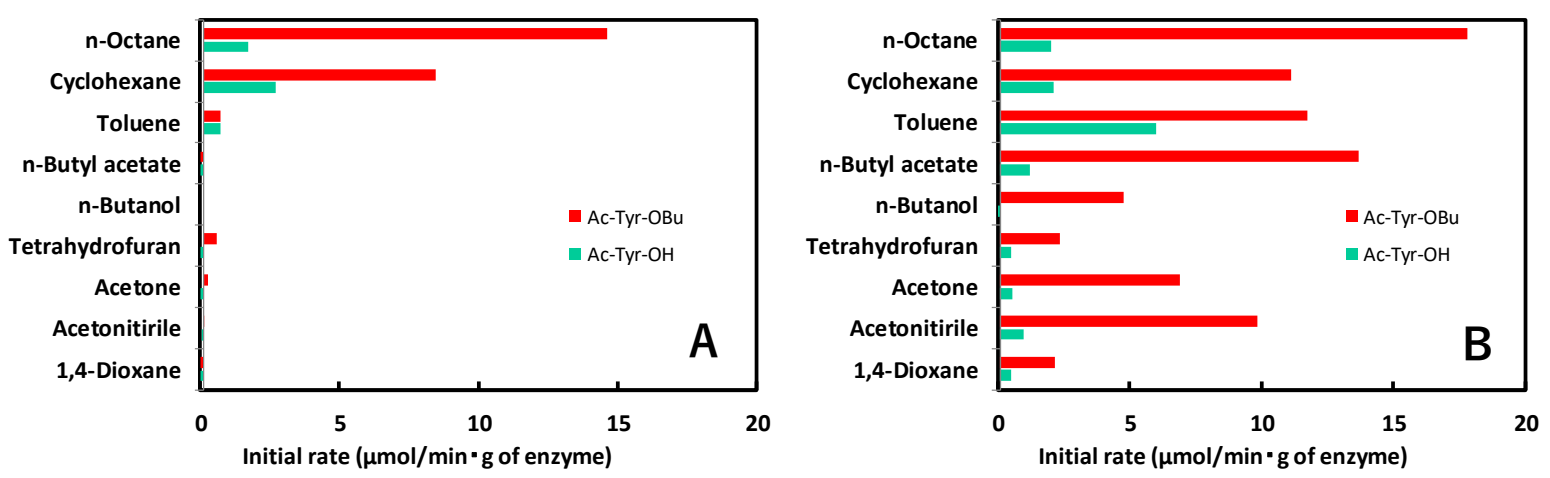

Figure 4. Solvent dependence of transesterification catalyzed by free $\alpha-\mathrm{CT}$ (A) and BCP-adsorbed $\alpha$-CT (B). Free or BCP-adsorbed $\alpha$-CT was placed in the organic solvent containing $0.2 \%(\mathrm{v} / \mathrm{v})$ water, $10 \mathrm{mM} N$-Ac-Tyr-OEt, 1000 $\mathrm{mM} \mathrm{BuOH}$, and $1 \mathrm{mM}$ acetanilide, and the resulting mixture was shaken at $120 \mathrm{rpm}$ and $25^{\circ} \mathrm{C}$
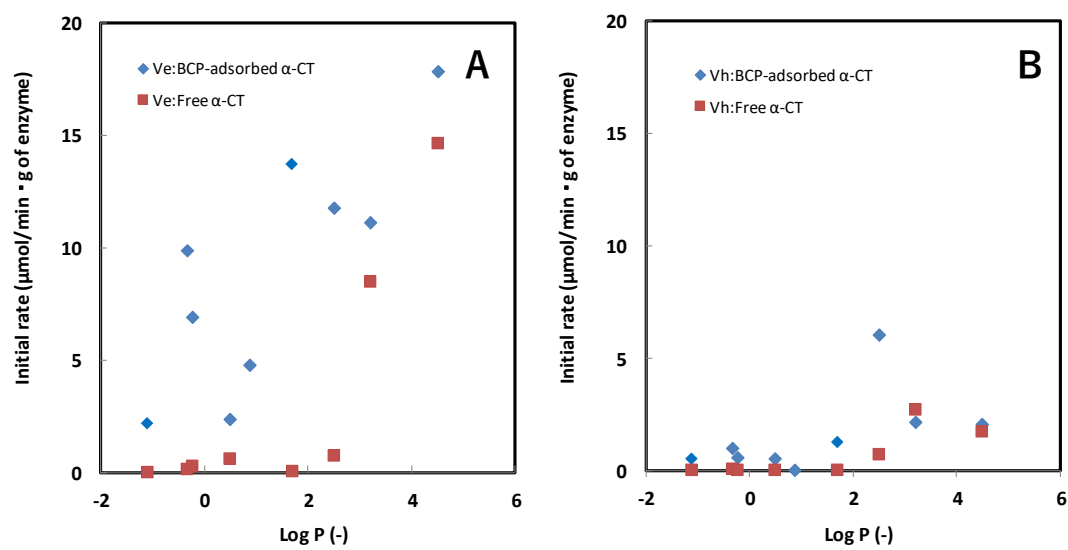

Figure 5. Relationship of $\log \mathrm{P}$ of organic solvents with transesterification rate (A) or hydrolysis rate (B) of free $\alpha-\mathrm{CT}$ and BCP-adsorbed $\alpha-\mathrm{CT}$ 


\section{Conclusions}

We have demonstrated that the nature of organic solvents affects the catalysis of free $\alpha$-CT and BCP-adsorbed $\alpha$-CT. BCP-adsorbed $\alpha$-CT exhibited the high catalytic activity, compared to the case of free $\alpha$-CT in organic solvents. Especially, the transesterification rate of BCP-adsorbed $\alpha$-CT was much superior to that of free $\alpha$-CT in hydrophilic organic solvents. The native conformation of BCP-adsorbed $\alpha$-CT did not change with the nature of organic solvents, while that of free $\alpha-\mathrm{CT}$ changed to some extent.

\section{References}

Bailey J. E., \& Ollas D. F. (1986). Biochemical Engineering Fundamentals $2^{\text {nd }}$ ed. McGraw-Hill.

Buchholz K., Kasche V., \& Bornscheuer U. T. (2012) Biocatalyst and Enzyme Technology $2^{\text {nd }}$ ed. Wiley-Blackwell.

Elnashar M. M. M. (2010). Review article: Immobilized molecules using biomaterials and nanobiotechnology. $J$. Biomaterials Nanobiotechnol., 1, 61-77.

Ho Y.C. \& Show K. Y. (2015). A perspective in renewable energy production from biomass pyrolysis-challenges and prospects. Current Organic Chem., 19, 423-436.

IPCC, Climate Change 2014 (2014) Synthesis Report, Intergovernmental Panel on Climate Change (IPCC), Geneva, Switzerland.

Kise H., Hayakawa A., \& Noritomi H. (1990). Protease-catalyzed synthetic reactions and immobilization-activation of the enzymes in hydrophilic organic solvents. J. Biotechnol., 14, 239-254.

Klibanov A. M. (2001). Improving enzymes by using them in organic solvents. Nature, 409, 241-246.

Kumar A. \& Venkatesu P. (2012) Overview of the stability of $\alpha$-chymotrypsin in different solvent media. Chemical Reviews, 112, 4283-4307.

Laane C., Boeren S., Vos K., \& Veeger C. (1987). Rules for optimization of biocatalysis in organic solvents. Biotechnol. Bioeng., 30, 81-87.

Leech D., Kavanagh P., \& Schuhmann W. (2012). Enzymatic fuel cells: Recent progress. Electrochimica Acta, 84, 223-234.

Leninger A. L., Nelson D. L., \& Cox M. M. (1993). Principles of Biochemistry (2nd ed.). Worth Publishers.

Mateo C., Palomo J. M., Fernandez-Lorente G., Guisan J. M., \& Fernandez-Lorente R. (2007). Improvement of enzyme activity, stability and selectivity via immobilization techniques. Enzyme Microbial Technol., 40, 1451-1463.

Mozhaev V.V., Khmelnitsky Y.L., Sergeeva M.V., Belova A.B., Klyachko N.L., Levashov A.V., \& Martinek K. (1989). Catalytic activity and denaturation of enzymes in water/organic cosolvent mixtures. $\alpha$-Chymotrypsin and laccase in mixed water/alcohol, water/glycol and water/formamide solvents. Eur. J. Biochem., 184, 597-602.

Noritomi H., Kai R., Iwai D., Tanaka H., Kamila R., Tanaka M., Muneki K., \& Kato S. (2011). Increase in thermal stability of proteins adsorbed on biomass charcoal powder prepared from plant biomass wastes. J. Biomedical Sci. Eng., 4, 692-698.

Noritomi H., Ishiyama R., Kai R., Iwai D., Tanaka M., \& Kato S. (2012). Immobilization of lysozyme on biomass charcoal powder derived from plant biomass wastes. J. Biomaterials Nanobiotechnol., 3, 446-451.

Noritomi H., Iwai D., Kai R., Tanaka M., \& Kato S. (2013a). Adsorption of lysozyme on biomass charcoal powder prepared from plant biomass wastes. J. Chem. Eng. Jpn., 46, 196-200.

Noritomi H., Hishinuma K., Kurihara S., Nishigami J., Takemoto T., Endo N., \& Kato S. (2013 ${ }^{b}$ ). Adsorption of $\alpha$-chymotrypsin on plant biomass charcoal. J. Surface Eng. Materials Adv. Technol., 3, 269-274.

Noritomi H., Kurihara S., Endo N., \& Kato S. (2014). Heat-resistant properties of $\alpha$-chymotrypsin adsorbed onto biomass charcoal powder. J. Biomaterials Nanobiotechnol., 5, 179-185.

Noritomi H., Kurihara S., Endo N., Kato S., \& Uchiyama K. (2016). Effect of adsorption condition on thermal stability of proteins adsorbed onto biomass charcoal powder. International J. GEOMATE, 11, 2123-2128.

Noritomi H., Nishigami J., Endo N., Kato S., \& Uchiyama K. (2017ª). Organic solvent-resistant properties of proteins adsorbed onto biomass charcoal powder. International J. GEOMATE, 12, 140-145. 
Noritomi H., Nishigami J., Endo N., Kato S., \& Uchiyama K. $\left(2017^{\mathrm{b}}\right)$. Influence of water activity on protease adsorbed on biochar in organic solvents. J. Materials Sci. Research, 6, 96-102.

Ryu K., Dordick J.S. (1992). How do organic solvents affect peroxidase structure and function? Biochemistry, 31, 2588-2598.

Silwana B., Horst C. V. D., \& Iwuoha E. (2014). Aerometric determination of cadmium, lead, and mercury metal ions using a novel polymer immobilized horseradish peroxidase biosensor system. J. Environmental Sci. Health Part A, 49, 1501-1511.

Olivier J.G.J., Muntean M., \& Peters J.A.H.W. (2017). Trends in Global $\mathrm{CO}_{2}$ Emissions: Report.

Straathof A. J. J. (2014). Transformation of biomass into commodity chemicals using enzymes or cells. Chem. Rev., 114, 1871-1908.

Surewicz W. K. \& Mantsch H. H. (1988). New insight into protein secondary structure from resolution-enhanced infrared spectra. Biochim. Biophys. Acta, 952, 115-130.

Wescott C.R., Noritomi H., Klibanov A.M. (1996). Rational control of enzymatic enantioselectivity through solvation thermodynamics. J. Am. Chem. Soc., 118, 10365-10370.

Zdata J., Meyer A.S., Jesionowski T., \& Pinelo M. (2018). A general overview of support materials for enzyme immobilization: characteristics, properties, practical utility. Catalysts, 8, 92-118.

Zaks A. \& Klibanov A.M. (1988). Enzymatic catalysis in nonaqueous solvents. J. Biol. Chem., 263, 3194-3201.

\section{Copyrights}

Copyright for this article is retained by the author(s), with first publication rights granted to the journal.

This is an open-access article distributed under the terms and conditions of the Creative Commons Attribution license (http://creativecommons.org/licenses/by/4.0/). 